\title{
Recommendations on screening for breast cancer in women aged 40-74 years who are not at increased risk for breast cancer
}

\author{
Scott Klarenbach MD MSc, Nicki Sims-Jones RN MScN, Gabriela Lewin MD, Harminder Singh MD MPH, \\ Guylène Thériault MD, Marcello Tonelli MD SM, Marion Doull PhD, Susan Courage RN BScN, \\ Alejandra Jaramillo Garcia MSc, Brett D. Thombs PhD; for the Canadian Task Force on Preventive Health Care
}

Cite as: CMAJ 2018 December 10;190:E1441-51. doi: 10.1503/cmaj.180463

This guideline is available in French at www.cmaj.ca/lookup/suppl/doi:10.1503/cmaj.180463/-/DC1

CMAJ Podcasts: interview in English at https://soundcloud.com/cmajpodcasts/180463-guide-eng; entrevue en français au https://soundcloud.com/cmajpodcasts/180463-guide-fre

See related article at www.cmaj.ca/lookup/doi/10.1503/cmaj.181538

B reast cancer mortality rates among Canadian women have declined from 41.7 per 100000 in 1988 to an estimated 23.2 per 100000 in 2017, while age-standardized incidence has remained relatively stable, at around 130 per 100000 since 2004. ${ }^{1}$ Declining mortality with stable incidence could reflect improvements in breast cancer treatment, timely detection of symptomatic cancer, screening programs, or all of these. ${ }^{1}$ Breast cancer screening programs have been in place in most regions of Canada since the early 1990s. In 2014, 54\% of women aged 50 to 69 years had been screened in the previous 30 months via a screening program, and an unknown number of women were screened outside of programs. ${ }^{2}$ Screening may identify breast cancer earlier and lead to more effective and less invasive treatment; however, it may also lead to overdiagnosis and subsequent treatment of cancer that, left untreated, would not have become apparent or caused harm. ${ }^{3}$ Examples of adverse sequelae of treatments (e.g., surgical intervention, radiotherapy, chemotherapy) include pain, disfigurement and distress. In addition, false-positive screening results may have a psychological impact and can lead to adverse physical effects from further testing. ${ }^{3}$

The systematic review ${ }^{4}$ that informed task force recommendations in $2011^{5}$ reported a reduction in breast cancer mortality with mammography screening for women aged 40 to 74 years. However, net benefit for women younger than 50 years was equivocal, given their lower absolute risk as well as their higher probability of being overdiagnosed and having false-positive screens compared with women aged 50 to 74 years. ${ }^{4}$ Current recommendations are informed by an updated evidence review of benefits and harms of breast cancer screening, as well as a new systematic review of women's values and preferences about screening.

\section{KEY POINTS}

- Low-certainty evidence indicates that screening for breast cancer with mammography results in a modest reduction in breast cancer mortality for women aged 40 to 74 years; the absolute benefit is lowest for women younger than 50 years.

- Screening may lead to overdiagnosis, resulting in unnecessary treatment of cancer that would not have caused harm in a woman's lifetime and false-positive results that can lead to both physical and psychological consequences; overdiagnosis and false-positives with related biopsies are more common in younger women.

- The balance of benefits and harms from screening is less favourable for women aged 40 to 49 years than for older women.

- Evidence on women's values and preferences about screening suggests that a substantial proportion of women aged 40 to 49 years would not choose to be screened if they were aware of the outcomes for their age group, but more older women would choose screening, given the more favourable balance of benefits and harms.

- In light of low-certainty evidence for benefits and harms from breast cancer screening, as well as variability in patient preferences, women should be supported to make an informed choice on screening that is congruent with their own values and preferences; women aged 50 to 74 years should be engaged in shared decision-making with their health care providers.

\section{Scope}

This guideline updates the task force's previous recommendations for primary care providers on breast cancer screening for women aged 40 to 74 years who are not at increased risk of breast cancer. ${ }^{5}$ Those considered to be at increased risk include women 
with a personal or family history of breast cancer; women who are carriers of gene mutations such as $B R C A 1$ or $B R C A 2$, or who have a first-degree relative with these gene mutations; and women who had chest radiation therapy before age 30 years or within the past 8 years. $^{6-13}$

\section{Methods}

The task force is an independent panel of clinicians and methodologists that makes recommendations on primary and secondary prevention in primary care (www.canadiantaskforce.ca). The current recommendations were developed by a working group of 6 task force members, with scientific support from Public Health Agency of Canada staff. ${ }^{14}$

Recommendations are based on 2 evidence reviews: the first on outcomes of breast cancer screening for women aged 40 years and older who are not at increased risk for breast cancer, ${ }^{15}$ and a second on women's values and preferences about screening. ${ }^{16}$ Review protocols were registered on PROSPERO (CRD42017051498; CRD42017058476) and are available at www.canadiantaskforce.ca. The analytic framework is provided in Appendix 1 (available at www.cmaj.ca/lookup/suppl/doi:10.1503/cmaj.180463/-/DC2).

The evidence review on screening outcomes was an overview of reviews with an updated search for new evidence, conducted by the Evidence Review and Synthesis Centre at the Ottawa Hospital Research Institute. ${ }^{15}$ Outcomes included all-cause and breast cancer mortality, overdiagnosis and false-positive results with ensuing biopsies. Eighteen systematic reviews were considered for inclusion and assessed for quality, completeness of reporting and fit for purpose, according to eligibility and methodological criteria. Systematic reviews produced for guidelines by the United States Preventive Services Task Force, ${ }^{17}$ American Cancer Society ${ }^{18}$ and Canadian Task Force on Preventive Health Care $^{4}$ were selected using these criteria. An initial search for additional primary studies published more recently was conducted using MEDLINE and the Cochrane Library from October 2014 to January 2017 for all screening modalities except breast self-examination, which was searched from October 2010, when the last review ${ }^{4}$ was conducted for the task force. Grey literature was also searched to January 2017. ${ }^{15}$

The University of Alberta's Evidence Review and Synthesis Centre conducted a systematic review of women's values and preferences on outcomes of breast cancer screening and how these valuations are used in decision-making. ${ }^{16}$ Studies of any design published from January 2000 to November 2016 in which women were asked about the relative importance of expected benefits and harms from breast cancer screening were identified from an initial search of MEDLINE, the Cochrane Library, CINAHL, PsycINFO and from the grey literature. ${ }^{16}$

The reviews ${ }^{15,16}$ and draft guideline were reviewed by content experts and stakeholders. The searches for both reviews were updated to December 2017 using the same keywords and databases, with evidence updated as required. A prepublication search for trial evidence on outcomes of screening was conducted in October 2018.

The Knowledge Translation Program at St. Michael's Hospital (Toronto, Ont.) developed knowledge translation tools that accompany this guideline, for clinicians and patients; these are published on the task force website (www.canadiantaskforce.ca).

The task force used the Grading of Recommendations, Assessment, Development and Evaluation (GRADE) approach to determine the quality or certainty of evidence and strength of recommendations (Box 1). ${ }^{19-21}$ Appendix 2 (available at www. cmaj.ca/lookup/suppl/doi:10.1503/cmaj.180463/-/DC2) provides the evidence-to-decision table for the recommendations.

\section{Management of competing interests}

Funding for the Canadian Task Force on Preventive Health Care is provided by the Public Health Agency of Canada. The views of the funding body have not influenced the content of the guideline. All task force members are required to disclose financial and nonfinancial competing interests. These statements are made publicly available on the task force website. All task force members declared that they had no competing interests for this guideline.

\section{Recommendations}

These recommendations apply to women aged 40 to 74 years who are not at increased risk of breast cancer. See Box 2 for a summary of recommendations.

\section{Screening using mammography}

The overview of reviews identified 8 randomized controlled trials (RCTs) or quasi-RCTs (Appendix 3, available at www.cmaj.ca/ lookup/suppl/doi:10.1503/cmaj.180463/-/DC2) 22-30 with information on benefits of breast cancer screening using mammography with or without clinical breast examination. ${ }^{15}$ Trials were begun between 1963 and 1991 in Sweden, Canada, the United States and the United Kingdom. The number of women randomized ranged from 18000 to 160000 , with mean follow-up from 18 to 30 years and screening intervals between 12 and 33 months. Duration of the screening period was from 3 to 12 years (median $7 \mathrm{yr}$ ) with participation rates of $65 \%$ to $88 \% .^{15}$

Low-certainty evidence from the 8 included trials found no statistically significant difference in overall all-cause mortality from screening using mammography, with 0.69 fewer deaths per 1000 women of all ages at moderate baseline risk (95\% confidence interval $[\mathrm{Cl}] 0.00$ to 1.38 fewer). ${ }^{15}$ Baseline risk refers to rates of breast cancer mortality among women in the control group (not targeted for screening) with corresponding low $(0.2 \%)$, moderate $(0.4 \%)$ and high $(0.6 \%)$ risk of breast cancer mortality, based on findings in the trials. ${ }^{15}$ Results for women aged 50 to 59 years are presented using the moderate baseline risk groups.

There were no statistically significant differences in relative risk of breast cancer mortality with screening between age subgroups $\left(I^{2}=0 \%, p=0.44\right) .{ }^{15}$ Thus, the all-ages relative risk has been applied to each of the age subgroups to calculate corresponding risk of breast cancer mortality ${ }^{31,32}$ (Table 1) (for calculations, see Appendix 4, available at www.cmaj.ca/lookup/suppl/ doi:10.1503/cmaj.180463/-/DC2).

In relation to harms of breast cancer screening using mammography, 3 trials ${ }^{38-40}$ and 6 cohort studies ${ }^{41-46}$ were identified 
that reported on overdiagnosis. However, only the Canadian $\mathrm{RCT}^{39}$ estimated rates of overdiagnosis by age in a trial judged to be at moderate risk of bias; these findings are presented in Table 2. ${ }^{15}$ Risk of bias may include such issues as failure to conceal allocation to group, failure to blind, loss to follow-up and not considering intention-to-treat, among others.

Rates of false-positive screens with resulting biopsies were calculated using data from the Canadian Partnership Against Cancer's ${ }^{2}$ 2011/12 cycle report. ${ }^{15,47}$ Table 3 presents estimated rates of false-positive screens and resulting biopsies for a cohort of 1000 women screened over 7 years (the median duration of screening in included trials), as well as the number of women to be screened to prevent a death from breast cancer.

No evidence was identified on the benefits and harms of screening women aged 75 years and older.

\section{Women aged 40 to 49 years}

For women aged 40 to 49 years, we recommend not screening with mammography; the decision to undergo screening is conditional on the relative value a woman places on possible benefits and harms from screening (conditional recommendation; lowcertainty evidence).

As shown in Table 1, there is low-certainty evidence that the absolute benefit of screening on breast cancer mortality for women aged 40 to 49 years is 0.58 fewer deaths per 1000 women screened for a median of 7 years $(95 \% \mathrm{Cl} 0.27$ to 0.85 fewer). The number needed to screen (NNS) to prevent a death from breast cancer is 1724 (95\% Cl 1176 to 3704). Among women aged 40 to 49 years, 5 years after screening, $41 \%$ of identified invasive and in situ cancers are estimated to be overdiagnosed, and 32\% of identified invasive cancers are estimated to be overdiagnosed (Table 2). Among 1000 women screened over 7 years, 294 will receive a false-positive result and 43 will undergo a biopsy (Table 3 ).

\section{Women aged 50 to 69 years}

For women aged 50 to 69 years, we recommend screening with mammography every 2 to 3 years; the decision to undergo screening is conditional on the relative value that a woman places on possible benefits and harms from screening (conditional recommendation; very low-certainty evidence).

Table 1 reports very low-certainty evidence that the absolute benefit of screening on breast cancer mortality for women aged 50 to 59 years is 0.75 fewer deaths per 1000 women who have been screened for a median of 7 years (95\% Cl 0.35 to 1.10 fewer). The NNS to prevent a death from breast cancer for women aged 50 to 59 years is $1333(95 \% \mathrm{Cl}$ 909 to 2857). Five years after screening, 25\% of identified invasive and in situ cancers are estimated to be overdiagnosed among women aged 50 to 59 years, and $16 \%$ of identified invasive cancers are estimated to be overdiagnosed (Table 2). Among 1000 women aged 50 to 59 years screened over 7 years, 294 will receive a false-positive result and 37 will undergo a biopsy (Table 3).

As indicated in Table 1, there is low-certainty evidence that for women aged 60 to 69 years, the absolute benefit of

\section{Box 1: Grading of recommendations}

Recommendations are graded according to the Grading of Recommendations Assessment, Development and Evaluation system (GRADE) ${ }^{19}$ Whether a recommendation is strong or conditional ${ }^{*}$ is based on considerations such as certainty in the effects of an intervention, including magnitude, as well as estimates of how patients value and prioritize outcomes, variability of these estimates and wise use of resources.

\section{Strong recommendations}

Strong recommendations are those for which the task force is confident that the desirable effects of an intervention outweigh its undesirable effects (strong recommendation for an intervention) or that the undesirable effects of an intervention outweigh its desirable effects (strong recommendation against an intervention). A strong recommendation implies that most people will be best served by the recommended course of action.

Strong recommendations are typically based on high-certainty evidence (i.e., high confidence in the estimate of the effect of an intervention). Strong recommendations may recommend in favour of an intervention (when there is high confidence of net benefit) or against an intervention (when there is high confidence of net harm). However, there are circumstances in which a strong recommendation may be considered based on low- or very low-certainty evidence or when there is absence of evidence. ${ }^{20}$

When there is an absence of evidence to provide confidence that there is benefit from implementing a new prevention service or when a conclusion of possible benefit requires a high level of speculation on linkages of uncertain evidence, but there is high certainty that some patients would be harmed or scarce health care resources expended, the task force may make a strong recommendation against service implementation. This is consistent with the GRADE approach, in which strong recommendations are sometimes made with low-certainty evidence combined with high certainty of harm or resource implications, and with the value that the task force places on using scarce primary care resources wisely.

\section{Conditional recommendations}

Conditional recommendations are those for which the desirable effects probably outweigh the undesirable effects (conditional recommendation in favour of an intervention) or undesirable effects probably outweigh the desirable effects (conditional recommendation against an intervention) but appreciable uncertainty exists. Conditional recommendations are made when the certainty of evidence is lower, when the margin between desirable and undesirable consequences is small and the balance depends on patient values and preferences, or when there is high variability in the values and preferences of patients. Conditional recommendations may also be applied when the balance of cost and benefits is ambiguous, key stakeholders differ about the acceptability or feasibility of the implementation, or the effects on health equity are unclear.

In certain cases where a conditional recommendation for an intervention is made, clinicians are encouraged to engage in shared decision-making, to recognize that different choices will be appropriate for individual patients, and to help each person arrive at a management decision consistent with their values and preferences.

Evidence is graded as high-, moderate-, low- or very low-certainty, based on how likely further research is to change the task force's confidence in the estimate of effect.

*The task force previously used the term "weak recommendation," but has replaced this with the term "conditional recommendation," to improve understanding and facilitate implementation of guidance, based on feedback from clinician knowledge users. One reason for this change was the value that the task force places on shared decisionmaking, together with a need to clarify better when implementation of a recommendation depends on circumstances such as patient values, resource availability or other contextual considerations. Conditional recommendations based on patient values and preferences require clinicians to recognize that different choices will be appropriate for different patients and those decisions must be consistent with each patient's values and preferences. Knowledge translation tools are available on the task force website (www. canadiantaskforce.ca) to facilitate decisions that are evidence informed and aligned with an individual's priorities. 


\section{Box 2: Recommendations}

Recommendations apply to women aged 40 to 74 years who are not at increased risk of breast cancer.

\section{Mammography}

- Screening women aged $\mathbf{4 0}$ to $\mathbf{4 9}$ years: For women aged 40 to 49 years, we recommend not screening with mammography; the decision to undergo screening is conditional on the relative value a woman places on possible benefits and harms from screening (conditional recommendation; low-certainty evidence).

- Screening women aged $\mathbf{5 0}$ to 69 years: For women aged 50 to 69 years, we recommend screening with mammography every 2 to 3 years; the decision to undergo screening is conditional on the relative value that a woman places on possible benefits and harms from screening (conditional recommendation; very lowcertainty evidence).

- Screening women aged $\mathbf{7 0}$ to $\mathbf{7 4}$ years: For women aged 70 to 74 years, we recommend screening with mammography every 2 to 3 years; the decision to undergo screening is conditional on the relative value that a woman places on possible benefits and harms from screening (conditional recommendation; very lowcertainty evidence).

\section{Other screening modalities}

- We recommend not using magnetic resonance imaging, tomosynthesis or ultrasound to screen for breast cancer in women who are not at increased risk (strong recommendation; no evidence).

- We recommend not performing clinical breast examinations to screen for breast cancer (conditional recommendation; no evidence).

- We recommend not advising women to practise breast selfexamination to screen for breast cancer (conditional recommendation; low-certainty evidence).

screening on mortality is 0.92 fewer deaths per 1000 women screened over 7 years $(95 \% \mathrm{Cl} 0.43$ to 1.35 fewer). The NNS to prevent a death from breast cancer for women aged 60 to 69 years is 1087 (95\% Cl 741 to 2326). No information is available on rates of overdiagnosis for women of this age. Among 1000 women aged 60 to 69 years screened over 7 years, 256 will receive a false-positive result and 35 will undergo a biopsy (Table 3).

\section{Women aged 70 to 74 years}

For women aged 70 to 74 years, we recommend screening with mammography every 2 to 3 years; the decision to undergo screening is conditional on the relative value that a woman places on possible benefits and harms from screening (conditional recommendation; very low-certainty evidence).

Table 1 shows very low-certainty evidence that the absolute benefit of screening on breast cancer mortality for women aged 70 to 74 years is 1.55 fewer deaths per 1000 women screened for a median of 7 years ( $95 \% \mathrm{Cl} 0.72$ to 2.27 fewer). The NNS to prevent a death from breast cancer in women aged 70 to 74 years is 645 (95\% Cl 441 to 1389). No information is available on rates of overdiagnosis for women of this age. Among 1000 women screened over 7 years, 219 will receive a false-positive result and 30 of them will undergo a biopsy (Table 3).

\section{Screening using modalities other than mammography} We recommend not using magnetic resonance imaging (MRI), tomosynthesis or ultrasound to screen for breast cancer in women who are not at increased risk (strong recommendation; no evidence).

No evidence was identified on the effect of breast cancer screening using MRI, tomosynthesis or ultrasound on outcomes important to patients. ${ }^{15}$ The recommendation is strong because these modalities would require the use of substantial and scarce health care resources when used for screening without evidence of benefit from their use.

We recommend not performing clinical breast examinations to screen for breast cancer (conditional recommendation; no evidence).

No evidence was identified on effectiveness of breast cancer screening using clinical breast examination. ${ }^{15}$

We recommend not advising women to practise breast selfexamination to screen for breast cancer (conditional recommendation; low-certainty evidence).

The evidence review ${ }^{15}$ identified 2 cluster randomized trials ${ }^{48,49}$ comparing breast self-examination to usual care. Lowcertainty evidence from these trials did not show that breast selfexamination as a screening modality reduced all-cause mortality (1.79 fewer deaths per 1000 women screened; 95\% Cl 5.36 more to 8.48 fewer)..$^{15}$ One of these trials ${ }^{49}$ also reported low-certainty evidence that self-examination likely does not reduce breast cancer mortality $(0.03$ more deaths per 1000 women screened: $95 \% \mathrm{Cl} 0.19$ fewer to 0.31 more). ${ }^{15}$

\section{Values and preferences}

Twenty-nine studies assessed the relative importance women placed on anticipated benefits and harms from breast cancer screening and how these valuations may have influenced screening decisions. ${ }^{16}$ The studies, most published after 2010 (range 2000-2017), were conducted in 11 different countries (1 in Canada) and had sample sizes from 6 to 16000 . They included 5 qualitative studies, ${ }^{50-54} 9$ RCTs, ${ }^{55-63} 1$ single-arm trial, ${ }^{64} 8$ cross-sectional surveys, ${ }^{65-72} 3$ uncontrolled pre-post studies, ${ }^{73-75} 2$ stated preference studies ${ }^{76,77}$ and a single deliberative jury. ${ }^{78}$ Studies varied widely in how information on benefits and harms was presented but tended to provide high benefit-to-harm ratios. ${ }^{16}$

There were 13 studies that directly addressed how women weigh benefits and harms (Appendix 5, available at www.cmaj. ca/lookup/suppl/doi:10.1503/cmaj.180463/-/DC2) and 16 that used screening attendance or intention to be screened to imply relative weights of outcomes based on data presented in decision aids or by other means (Appendix 6, available at www.cmaj. ca/lookup/suppl/doi:10.1503/cmaj.180463/-/DC2). Studies in both sets provided information on how other factors influenced outcome valuations and screening decisions. ${ }^{16}$

Of women aged 40 to 49 years, a substantial proportion appear to reduce or reverse their initial perceptions of a high benefit-toharm ratio for breast cancer screening when provided with accurate estimates on the absolute benefits and harms for their age group. ${ }^{16}$

For most women aged 50-69 years, reduction in breast cancer mortality from screening appears to outweigh concerns about 


\begin{tabular}{|c|c|c|c|c|c|c|c|c|c|c|}
\hline & & & $\begin{array}{l}\text { Women who } \\
\text { breast canc }\end{array}$ & $\begin{array}{l}\text { from } \\
\% \dagger\end{array}$ & & & & & & \\
\hline $\begin{array}{l}\text { Age, } \\
\text { yr }\end{array}$ & $\begin{array}{c}\text { Range } \\
\text { of } \\
\text { follow- } \\
\text { up, yr }\end{array}$ & $\begin{array}{l}\text { No. and } \\
\text { design of } \\
\text { studies }\end{array}$ & $\begin{array}{l}\text { Mammogram } \\
\text { with or } \\
\text { without } \\
\text { clinical breast } \\
\text { examination }\end{array}$ & $\begin{array}{c}\text { Usual } \\
\text { care, } \\
\%\end{array}$ & $\begin{array}{l}\text { Women } \\
\text { who are } \\
\text { not } \\
\text { screened: } \\
\text { risk of } \\
\text { dying of } \\
\text { breast } \\
\text { cancer per } \\
1000^{15}\end{array}$ & $\begin{array}{c}\text { Relative risk } \\
\qquad(95 \% \mathrm{Cl}) \ddagger\end{array}$ & $\begin{array}{l}\text { who are } \\
\text { screened: } \\
\text { risk of } \\
\text { dying } \\
\text { from } \\
\text { breast } \\
\text { cancer per } \\
1000 \\
(95 \% \mathrm{Cl})\end{array}$ & $\begin{array}{c}\text { Absolute } \\
\text { effect per } \\
1000 \\
(95 \% \mathrm{Cl})\end{array}$ & $\begin{array}{l}\text { Number } \\
\text { needed to } \\
\text { screen } \\
(95 \% \mathrm{Cl})\end{array}$ & $\begin{array}{c}\text { GRADE rating } \\
\text { of certainty } \\
\text { of evidence }\end{array}$ \\
\hline $\begin{array}{l}40- \\
49\end{array}$ & $\begin{array}{c}17.7 \text { to } \\
25.7\end{array}$ & $\begin{array}{c}8 \mathrm{RCTS}^{23,33-37} \\
\uparrow\end{array}$ & Unavailablet† & 0.4 & 3.85 & $\begin{array}{c}0.85 \\
(0.78 \text { to } 0.93)\end{array}$ & $\begin{array}{c}3.27 \\
(3.00 \text { to } \\
3.58)\end{array}$ & $\begin{array}{c}0.58 \text { fewer } \\
\text { (0.27 fewer } \\
\text { to } 0.85 \\
\text { fewer) }\end{array}$ & $\begin{array}{c}1724 \\
\text { (1176 to } 3704)\end{array}$ & $\begin{array}{l}\oplus \oplus \mathrm{OO} \\
\text { LOW } \ddagger\end{array}$ \\
\hline $\begin{array}{l}50- \\
59 \S\end{array}$ & $\begin{array}{c}18 \text { to } \\
30\end{array}$ & $6 \mathrm{RCTs}^{33,35-37} \mathbf{q}$ & Unavailablet† & 0.5 & 5.00 & $\begin{array}{c}0.85 \\
(0.78 \text { to } 0.93)\end{array}$ & $\begin{array}{c}4.25 \\
(3.90 \text { to } \\
4.65)\end{array}$ & $\begin{array}{c}0.75 \text { fewer } \\
\text { (from } 0.35 \\
\text { fewer to } \\
1.10 \text { fewer) }\end{array}$ & $\begin{array}{c}1333 \\
\text { (909 to 2857) }\end{array}$ & $\begin{array}{c}\oplus \mathrm{OOO} \\
\text { VERY LOW§§ }\end{array}$ \\
\hline $\begin{array}{l}60- \\
69\end{array}$ & $\begin{array}{c}13.1 \text { to } \\
30\end{array}$ & $\begin{array}{c}4 \mathrm{RCTs}^{23,33,35-} \\
36 \star \star\end{array}$ & Unavailablet† & 0.6 & 6.15 & $\begin{array}{c}0.85 \\
(0.78 \text { to } 0.93)\end{array}$ & $\begin{array}{c}5.23 \\
(4.80 \text { to } \\
5.72)\end{array}$ & $\begin{array}{c}0.92 \text { fewer } \\
\text { (from } 0.43 \\
\text { fewer to } \\
1.35 \text { fewer) }\end{array}$ & $\begin{array}{c}1087 \\
\text { (741 to } 2326)\end{array}$ & $\begin{array}{l}\oplus \oplus \mathrm{OO} \\
\text { LOW } \ddagger\end{array}$ \\
\hline $\begin{array}{l}70- \\
74\end{array}$ & $\begin{array}{c}13.2 \text { to } \\
13.6\end{array}$ & $2 \mathrm{RCTs}^{23,35}$ & Unavailablet† & 1.0 & 10.31 & $\begin{array}{c}0.85 \\
(0.78 \text { to } 0.93)\end{array}$ & $\begin{array}{c}8.76 \\
(8.04 \text { to } \\
9.59)\end{array}$ & $\begin{array}{c}1.55 \text { fewer } \\
\text { (from } 0.72 \\
\text { fewer to } \\
2.27 \text { fewer) }\end{array}$ & $\begin{array}{c}645 \\
\text { (441 to } 1389)\end{array}$ & $\begin{array}{c}\oplus O O O \\
\text { VERY LOW ฯฯ }\end{array}$ \\
\hline
\end{tabular}

Note: $\mathrm{Cl}=$ confidence interval, GRADE = Grading of Recommendations Assessment, Development and Evaluation system, RR = relative risk

*This table presents screening outcomes based on short-case accrual methods. The systematic review conducted for this guideline presents screening outcomes using both short- and long-case accrual methods. ${ }^{15}$ In short-case accrual (initial + 7 subsequent screens; 23 years of follow-up), only those cases diagnosed during the screening period are included (median $7 \mathrm{yr}$; range 3 to $12 \mathrm{yr}$ ), whereas long-case accrual (initial + 4 subsequent screens; 14 years of follow-up) includes all cases diagnosed to the end of the follow-up period. Short-case accrual reduces bias from contamination because women in the control group would not have been screened until the trial was over, while long-case accrual may underestimate the benefits of screening as women in the control group are more likely being screened after the trial. ${ }^{15}$

†The baseline risk in the control groups may not have been representative of all included studies because the numerators or denominators were either unclear or not reported. $\ddagger$ A subgroup analysis of relative risk by age was assessed based on published methodology. ${ }^{31,32}$ No difference in RR among subgroups was detected and true differences resulting from age were deemed unlikely. The use of the all-ages RR data rather than focusing on each decade of age aligns with this assessment. It is appropriate to use control event rates relevant to each age group to determine corresponding risks, with attendant implications on absolute benefit (calculations provided in Appendix 4).

$\S$ Presents results with control group at moderate baseline risk.

IThe Stockholm and Gothenburg trials were considered quasi-randomized ${ }^{33}$

${ }^{\star \star}$ The Stockholm trial was considered quasi-randomized. ${ }^{23}$

††Complete data were not available. Numerators or denominators were either unclear or not reported for all included studies.

$\ddagger$ $¥$ ery serious concerns about risk of bias because randomization and allocation concealment were either not reported or had serious deficiencies.

$\S \S$ Very serious concerns about risk of bias because randomization and allocation concealment were either not reported or had serious deficiencies and there were serious concerns about inconsistency, as heterogeneity may be moderate $\left(l^{2}=26 \% ; p\right.$ value $\left.=0.24\right)$ and there were serious concerns about imprecision because, although the number of events and total population are large (> 300 threshold for events), the $95 \%$ Cls include the null and do cross appreciable benefit (RR 0.75 ).

ฯฯ Very serious concerns about risk of bias because randomization and allocation concealment were either not reported or had serious deficiencies and there were serious concerns about imprecision because, although the total population is large (> 2000), the $95 \%$ Cls include the null and do cross appreciable benefit (RR 0.75 ).

potential harms. When provided with a brief description of overdiagnosis, women showed acceptance of relatively high rates of overdiagnosis with screening. On the other hand, when more detailed information on overdiagnosis was provided, some women said that screening was no longer attractive. Those who had been screened regularly maintained high intentions to continue to be screened regardless of how benefit-to-harm ratios were presented. ${ }^{16}$

For healthy women in their 70s, it appears that acceptance of screening may be quite high, perhaps because they have been screened for many years. ${ }^{16}$

For some women of all ages, other outcomes, including consequences of a false-negative screen, reassurance and the possibility of milder treatment courses, held importance. Beliefs about the severity and harms of breast cancer screening, such as viewing overdiagnosis as a consequence of treatment rather than screening, also influenced decisions about screening. In general, studies found that most women, regardless of age, value the opportunity to make informed decisions about screening that are consistent with their values and preferences. ${ }^{16}$

\section{Resource use}

A systematic review on cost-effectiveness of breast cancer screening was not conducted. Estimates from Statistics Canada (2015) on resources used by screening programs for breast 
Table 2: Estimated proportion of breast cancers overdiagnosed from screening ${ }^{\star 15}$

\section{Age of \\ women at \\ initial \\ screen, yr \\ Years after screening}

40 to 49

5

20

5

20

0

50 to 59

5

*Overdiagnosis by age was estimated using this calculation: The numerator is the difference in numbers of cancers in the mammography arm less those in the control arm; and the denominator is the number of screen-detected cancers in the mammography arm. ${ }^{39}$ Only the findings from the estimate on overdiagnosis from a Canadian randomized controlled trial ${ }^{39}$ are included because it provided an estimate by age and was appraised as being at moderate risk of bias..$^{15}$

Table 3: False-positives and unnecessary biopsies from an estimated cohort of women in a breast screening program for 7 years of screening ${ }^{\star 47}$

\begin{tabular}{|c|c|c|c|c|}
\hline \multirow[b]{2}{*}{ Outcome } & \multicolumn{4}{|c|}{ Age range, yr } \\
\hline & 40-49 & $50-59$ & $60-69$ & 70-74 \\
\hline \multicolumn{5}{|c|}{ Per 1000 women screened $\dagger$} \\
\hline FP mammography & 294 & 294 & 256 & 219 \\
\hline Biopsies on FP & 43 & 37 & 35 & 30 \\
\hline \multicolumn{5}{|c|}{ Per 1 breast cancer death prevented } \\
\hline $\begin{array}{l}\text { FP mammography } \\
\text { (based on } 3 \text { cycles of } \\
\text { screening) } \dagger\end{array}$ & 508 & $392(M)$ & 278 & 141 \\
\hline $\begin{array}{l}\text { Biopsies on FP } \\
\text { (based on } 3 \text { cycles of } \\
\text { screening) } \dagger\end{array}$ & 74 & $50(M)$ & 38 & 19 \\
\hline \multicolumn{5}{|c|}{$\begin{array}{l}\text { Note: } F P=\text { false-positive, } M=\text { calculated using the moderate baseline risk for this } \\
\text { age group. }{ }^{15} \\
\text { “As the median duration of screening trials was } 7 \text { years (range 3-12 yr), the impact of } \\
\text { this duration of screening on benefits and harms was used. The data are used to } \\
\text { approximate a cohort of women entering the screening programm. }{ }^{47} \text { Although assumed, } \\
\text { but not confirmed, the "initial screen" in the Canadian Partnership Against Cancer } \\
\text { report is the first screen documented in the database and may not necessarily be the } \\
\text { first "true" screen of a woman. This is especially true for data originating from Alberta. } \\
\text { Three cycles of screening for which women are screened every } 2-3 \text { years, for a total } \\
\text { of } 6-9 \text { years of a screening period. Calculation: Initial screening cycle + } 2 \text { (subsequent } \\
\text { screening cycle) to estimate harms occurring with } 7 \text { years of screening. }\end{array}$} \\
\hline
\end{tabular}

cancer suggest that costs for screening alone vary by screening interval and age of women at initiation of screening. ${ }^{79}$

\section{Feasibility, acceptability, cost and equity}

Screening programs for breast cancer have been in place across Canada since the early $1990 \mathrm{~s} .{ }^{1}$ In the judgment of the task force, current recommendations are both feasible and acceptable to women and clinicians and are not expected to have an increased negative effect on health equity or to pose additional costs to the health care system.

\section{Rationale}

The task force judged that no change was required in the direction of its previous recommendations on breast cancer screening with mammography, although the certainty of evidence (previously referred to as "quality of evidence") ${ }^{21}$ was downgraded upon reappraisal because of serious concerns regarding risk of bias in the original studies. ${ }^{15}$ As mentioned previously, no evidence was identified on the benefits and harms of screening women aged 75 years and older.

The absolute benefit of breast cancer screening with mammography remains lowest for younger women, with the balance of benefits and harms becoming more favourable with increasing age. Women aged 40 to 74 years should be supported to make an informed choice on breast cancer screening that is congruent with their own values and preferences. Knowledge translation tools are provided on the task force website to support this process.

Recommendations on screening mammography are conditional because of very low- to low-certainty evidence, uncertain balance of benefits and harms and variation in women's values and preferences, underlining the need for shared decisionmaking between women and their health care providers. Shared decision-making supports evidence-based and values-informed screening decisions. ${ }^{80-82}$

An earlier task force recommendation against MRI was updated to include tomosynthesis and ultrasound. As previously with MRI, no evidence was identified that assessed effectiveness of these modalities for screening purposes. No additional evidence was identified to inform previous recommendations on breast self-examination or clinical breast examination.

Recommendations for clinical and self-breast examination are conditional against screening based on the absence of evidence of benefit and the potential risk of harm to some women. There is a lack of evidence on the effectiveness of other screening modalities, and as their use in screening would consume scarce resources, the task force made a strong recommendation against their use.

\section{Women aged 40 to 49 years}

There is low-certainty evidence that women aged 40 to 49 years who are not at increased risk have a modest absolute reduction in breast cancer mortality from screening. Compared with women aged 50 years and older, they have higher rates of overdiagnosis with resulting harms from treatment for a cancer that would not have caused harm in their lifetime, and they are more likely to see consequences from false-positive screens, including biopsies. ${ }^{15}$ Evidence on women's preferences suggests that a substantial proportion of women would not choose to be screened if they knew their age group's absolute risk reduction for breast cancer mortality and increased potential for harm from screening. ${ }^{16}$

After balancing the overall benefits and harms of screening, and considering the values and preferences of these women, in the judgment of the task force, the undesirable effects of overdiagnosis and consequences of false-positive results outweigh potential benefits; therefore, the recommendation is against screening women of this age. This recommendation is conditional, as some 
women in this age group may wish to be screened, based on their values and preferences; in this circumstance, care providers should engage in shared decision-making with women who express an interest in being screened.

\section{Women aged 50 to 69 years}

There is very low-certainty evidence that women aged 50 to 69 years who are not at increased risk have a modest absolute reduction in breast cancer mortality from screening. ${ }^{15}$ Rates of overdiagnosis and consequences of false-positive screening results, although lower than for younger women, remain a concern. Women in this age group generally weigh even modest reductions in breast cancer mortality as more important than harms in their decision to be screened. ${ }^{16}$

In balancing the overall benefits and harms of screening for women aged 50 to 69 years, and considering their values and preferences, the task force places greater weight on women's preferences for screening to reduce breast cancer mortality by a modest amount than on harms, and therefore recommends in favour of screening using mammography every 2 to 3 years. Care providers should engage women of this age in shared decisionmaking because those who place a higher value on avoiding harms, compared with a modest absolute reduction in breast cancer mortality, may choose to not undergo screening.

\section{Women aged 70 to 74 years}

There is very low-certainty evidence of a modest absolute reduction in breast cancer mortality for women aged 70 to 74 years who are not at increased risk, and the consequences of falsepositive screening results remain a concern. No evidence was identified on the risk of overdiagnosis for these women. ${ }^{15}$ Healthy women of this age generally accept screening, perhaps owing to familiarity. ${ }^{16}$

In balancing the overall benefits and harms, the task force places relatively more weight on women's acceptance of screening programs in the context of a modest absolute reduction in breast cancer mortality, and lower weight on the risk of harms, and thus recommends in favour of screening these women using mammography every 2 to 3 years. Care providers should engage in shared decision-making with women of this age, because those who place a higher value on avoiding harms, compared with a modest absolute reduction in breast cancer mortality, may choose to not undergo screening.

\section{Considerations for implementation}

The recommendations focus on breast cancer screening using mammography because of the absence of evidence on patientimportant outcomes of screening with other modalities and evidence that performing self-breast examination for screening has no impact on breast cancer mortality. ${ }^{15}$ The recommendation is to screen women every 2 to 3 years, because screening intervals in the trials ranged from 12 to 33 months with a pooled analysis indicating similar benefits across intervals. ${ }^{4}$

There is some evidence that women with dense breast tissue are more likely to develop breast cancer than women without dense breasts. ${ }^{83-85}$ Increased breast density is more common among women aged 40 to 49 years than in those aged 50 years and older. ${ }^{86}$ However, classification of breast density status has poor reliability, and density status is reclassified on subsequent examination for 1 in 5 women by the same radiologist and for 1 in 3 by a different radiologist. ${ }^{87}$ Further, supplemental screening may increase the number of women experiencing overdiagnosis with unnecessary treatment and negative effects from falsepositive results. ${ }^{87} \mathrm{~A}$ recent review conducted for the US Preventive Services Task Force did not identify evidence on patientimportant outcomes from supplemental screening of women with dense breast tissue following a negative mammogram, and as such, its benefit is unknown. ${ }^{87}$

\section{Performance measures for implementation}

The task force suggests that quality assurance indicators for screening programs for breast cancer continue to be monitored through the Canadian Partnership Against Cancer, including false-positive rates and resulting biopsies, as well as stage of cancer at diagnosis. The recommendations on screening for breast cancer are conditional on women's values and preferences, which means that not all women aged 50 to 74 years should be screened. Quality improvement programs should focus on ensuring that decision-making is shared between women aged 50 to 74 years and their health care providers, as the ideal proportion of women to be screened is unknown. Strategies that promote increasing the proportion of women screened (such as through financial inducements) instead of the shared decision-making process are not aligned with these recommendations.

\section{Other guidelines}

Current task force recommendations for breast cancer screening are consistent with previous task force guidance and with major national guideline developers. As indicated in Table 4, some stakeholders specializing in cancer care have differing recommendations for screening.

\section{Gaps in knowledge}

More and better-quality evidence is needed on the impact of breast cancer screening for women of all ages, and particularly for women younger than 50 years and older than 70 . These populations are currently the focus of the AgeX Trial, a cluster randomized trial underway in the United Kingdom with results expected in 2026 (ClinicalTrial.gov, no. NCT01081288).

Although the task force did not specifically review evidence on supplemental screening for women with dense breast tissue, a recent review for the US Preventive Services Task Force concluded that studies are needed to clarify approaches to classification and called for rigorous comparative studies to determine patient-important outcomes of supplemental screening. ${ }^{87}$

Hanley and colleagues have proposed alternative approaches to interpreting screening outcomes because of diminishing returns from screening after its cessation. These authors recommend calculating 
Table 4 (part 1 of 2): National and international guidelines on breast cancer screening

\section{Organization}

Canadian Task Force on Preventive Health Care (current guideline, 2018)

Canadian Task Force on Preventive Health Care $(2011)^{5}$

United States Preventive Services Task Force $(2016)^{88}$

American Cancer Society $(2015)^{89}$

\section{Recommendations}

Recommendations apply to breast cancer screening for women aged 40 to 74 years who are not at increased risk of breast cancer:

\section{Mammography:}

- For women aged 40 to 49 years, we recommend not screening with mammography; the decision to undergo screening is conditional on the relative value a woman places on possible benefits and harms from screening (conditional recommendation; low-certainty evidence).

- For women aged 50 to 69 years, we recommend screening with mammography every 2 to 3 years; the decision to undergo screening is conditional on the relative value that a woman places on possible benefits and harms from screening (conditional recommendation; very low-certainty evidence).

- For women aged 70 to 74 years, we recommend screening with mammography every 2 to 3 years; the decision to undergo screening is conditional on the relative value that a woman places on possible benefits and harms from screening (conditional recommendation; very low-certainty evidence).

\section{Other screening modalities:}

Recommendations on using screening modalities other than mammography for breast cancer screening:

- We recommend not using MRI, tomosynthesis or ultrasound to screen for breast cancer in women who are not at increased risk (strong recommendation; no evidence).

- We recommend not performing clinical breast examinations to screen for breast cancer (conditional recommendation; no evidence).

- We recommend not advising women to practise breast self-examination to screen for breast cancer (conditional recommendation; low-certainty evidence).

Recommendations apply to women aged 40 to 74 years at average risk of breast cancer:

\section{Mammography:}

- For women aged 40-49 years, we recommend not routinely screening with mammography (weak recommendation; moderate-quality evidence).

- For women aged 50-69 years, we recommend routinely screening with mammography every 2 to 3 years (weak recommendation; moderate-quality evidence).

- For women aged 70-74 years, we recommend routinely screening with mammography every 2 to 3 years (weak recommendation; low-quality evidence).

MRI:

- We recommend not routinely screening with MRI scans (weak recommendation; no evidence).

\section{Clinical breast examination:}

- We recommend not routinely performing clinical breast examinations alone or in conjunction with mammography to screen for breast cancer (weak recommendation; low-quality evidence).

\section{Breast self-examination:}

- We recommend not advising women to routinely practise breast self-examination (weak recommendation; moderate-quality evidence).

Biennial screening mammography for women aged 50 to 74 years (Grade B recommendation).

The decision to start screening mammography in women before age 50 years should be an individual one. Women who place a higher value on the potential benefit than the potential harms may choose to begin biennial screening between 40 and 49 years of age (Grade $C$ recommendation).

For women aged 75 years or older, current evidence is insufficient to assess the balance of benefits and harms of screening mammography (Istatement).

For all women, current evidence is insufficient to assess the benefits and harms of digital breast tomosynthesis as a primary screening method for breast cancer (Istatement).

For women with dense breasts, current evidence is insufficient to assess the balance of benefits and harms of adjunctive screening for breast cancer following a negative mammogram using breast ultrasonography, MRI, digital breast tomosynthesis, or other methods in women identified to have dense breasts on an otherwise negative screening mammogram (I statement).

Women with an average risk of breast cancer should undergo regular screening mammography starting at age 45 years (strong recommendation).

Women aged 45 to 54 years should be screened annually, transitioning to biennial screening at 55 years of age with the option to continue annual screening (qualified recommendations).

Women between the ages of 40 and 44 years should have the opportunity to begin annual screening (qualified recommendation).

Healthy women should continue screening mammography as long as they have a life expectancy of 10 years or longer (qualified recommendation).

The American Cancer Society does not recommend clinical breast examination for breast cancer screening among average-risk women at any age (qualified recommendation). 
Table 4 (part 2 of 2): National and international guidelines on breast cancer screening

\section{Organization}

UK National Health

Service Breast Screening

Programme $(2015)^{90}$

Cancer Australia (2015) ${ }^{91}$

\section{Recommendations}

The UK National Screening Committee recommends that all eligible women aged 50 to 70 years be invited to breast cancer screening every 3 years.

Eligible women, aged 50 to 70 , receive an invitation letter explaining the program, as well as benefits and risks of breast screening:

- Women do not always receive an invitation when they turn 50. They can expect their invitation within 3 years of their 50th birthday.

- Women cannot walk in and request breast screening unless they are older than 70 , when they can request screening every 3 years.

It is recommended that women of all ages, and regardless of whether they attend mammographic screening, are aware of how their breasts normally look and feel and report any new or unusual changes promptly to their general practitioner.

No one method for women to use when checking their breasts is recommended over another.

It is recommended, to reduce the risk of death from breast cancer, that women aged 50-74 years attend the BreastScreen Australia Program for free 2-yearly screening mammograms, having considered the benefits and downsides.

Mammographic screening is not recommended for women younger than 40 years of age.

Women aged 40-49 years and 75 years and older are eligible to receive free screening mammograms through the BreastScreen Australia Program, but they do not receive an invitation to attend. In deciding whether to attend for screening mammography, women in these age groups should balance the potential benefits and downsides for them. For women of all ages who are at increased risk of developing breast cancer, it is recommended that an individualized surveillance program be developed in consultation with the woman's general practitioner or specialist.

Note: MRI = magnetic resonance imaging.

breast cancer mortality rates by year of screening rather than estimating cumulative mortality. ${ }^{92}$

Greater understanding of the risk of overdiagnosis from screening requires a common definition and agreed-upon denominator, as well as more rigorous study, particularly for women aged 60 to 74 years. ${ }^{3}$ Additional studies on values and preferences of Canadian women regarding screening, conducted using accurate estimates of both benefits and harms, would assist in guiding future recommendations. Finally, better estimates of the costs of breast cancer screening would also support guidance on screening.

\section{Conclusion}

Based on 2 evidence reviews, the task force has determined that recommendations for screening women for breast cancer should remain similar to those in the 2011 task force guideline. ${ }^{5}$ Although breast cancer screening has the potential to reduce breast cancer mortality, it increases risk of harms, particularly because of the risk of overdiagnosis, leading to unnecessary treatment and consequent adverse sequelae. Women should be supported to make an informed decision on screening that fits with their values and preferences. Future challenges include reducing uncertainty in estimates of benefits and harms from screening and gaining a greater understanding of values and preferences of Canadian women about breast cancer screening.

\section{References}

1. Canadian Cancer Society's Advisory Committee on Cancer Statistics. Canadian cancer statistics 2017. Toronto: Canadian Cancer Society; 2017. Available: cancer. ca/Canadian-CancerStatistics-2017-EN.pdf (accessed 2017 Nov. 5).

2. Breast cancer screening in Canada: monitoring \& evaluation of quality indicators. Special topic: spotlight on benefits and harms. Results report: January 2011December 2012. Toronto: Canadian Partnership Against Cancer; 2017.
3. Independent UK Panel of Breast Cancer Screening. The benefits and harms of breast cancer screening: an independent review. Lancet 2012;380:1778-86.

4. Fitzpatrick-Lewis D, Hodgson N, Ciliska D, et al. Breast cancer screening. Hamilton (ON): McMaster University; 2011.

5. Tonelli M, Connor Gorber S, Joffres M; Canadian Task Force on Preventive Health Care. Recommendations on screening for breast cancer in average-risk women aged 40 to 74 years. CMAJ 2011;183:1991-2001.

6. Breast cancer risk factors. Oxford (UK): Cancer Research UK. Available: www. cancerresearchuk.org/health-professional/cancer-statistics/statistics-by-cancer-type/ breast-cancer/risk-factors (accessed 2017 Nov. 3).

7. Cancer screening guidelines: breast, cervical \& colorectal. Toronto: Cancer Care Ontario; 2016; revised October 2016. Available: www.cancercareontario.ca/en/ types-of-cancer/breast-cancer/screening (accessed 2017 Nov. 3).

8. Kleibl Z, Kristensen VN. Women at high risk of breast cancer: molecular characteristics, clinical presentation and management. Breast 2016;28:136-44.

9. Garber JE, Offit K. Hereditary cancer predisposition syndromes. J Clin Oncol 2005;23:276-92.

10. Breast cancer risk and prevention. Atlanta: American Cancer Society. Available: www.cancer.org/cancer/breast-cancer/risk-and-prevention.html (accessed 2017 Nov. 5).

11. Nelson HD, Zakher B, Cantor A, et al. Risk factors for breast cancer for women aged 40 to 49 years: a systematic review and meta-analysis. Ann Intern Med 2012; 156:635-48.

12. Mavaddat N, Antoniou AC, Easton DF, et al. Genetic susceptibility to breast cancer. Mol Oncol 2010;4:174-91.

13. Antoniou A, Pharoah PDP, Narod S, et al. Average risks of breast and ovarian cancer associated with BRCA1 or BRCA2 mutations detected in case series unselected for family history: a combined analysis of 22 studies. Am J Hum Genet 2003;72:1117-30.

14. Canadian Task Force on Preventive Health Care procedure manual. Canadian Task Force on Preventive Health Care; 2014. Available: http//canadiantaskforce.ca/ methods/ (accessed 2017 Oct. 5).

15. Barbeau P, Stevens A, Beck A, et al. Breast cancer screening: Part A. An evidence report to inform an update of the Canadian Task Force on Preventive Health Care 2011 guideline (Prepared by the Knowledge Synthesis Group, Ottawa Methods Centre, Ottawa Hospital Research Institute for the Canadian Task Force on Preventive Health Care under contract by the Public Health Agency of Canada). CTFPHC; 2017. Available: www.canadiantaskforce.ca (accessed 2017 Oct. 9).

16. Pillay J, MacGregor T, Hartling L, et al. Breast Cancer Screening: Part B. Systematic review on women's values and preferences to inform an update of the Canadian Task Force on Preventive Health Care 2011 guideline. (Prepared by the Alberta Evidence Review and Synthesis Centre for the Canadian Task Force on Preventive Health Care under contract by the Public Health Agency of Canada). CTFPHC; 2017. Available: www.canadiantaskforce.ca (accessed 2017 Oct. 9). 
17. Nelson HD, Fu R, Cantor A, et al. Effectiveness of breast cancer screening: systematic review and meta-analysis to update the 2009 U.S. Preventive Services Task Force recommendation. Ann Intern Med 2016;164:244-55.

18. Duke Evidence Synthesis Group. Systematic review of cancer screening literature for updating American Cancer Society breast cancer screening guidelines. Atlanta: American Cancer Society; 2014. Available: www.cancer.org/content/dam/cancer-org/ cancer-control/en/reports/complete-systematic-evidence-review-acs-breast-cancer -screening-guideline.pdf (accessed 2017 Oct. 24).

19. Schünemann H, Brożek J, Guyatt G, editors. GRADE handbook. GRADE Working Group; 2013. Available: http://gdt.guidelinedevelopment.org/app/handbook/ handbook.html (accessed 2017 Jan. 16).

20. Andrews JC, Schünemann HJ, Oxman AD, et al. GRADE guidelines: 15. Going from evidence to recommendation-determinants of a recommendation's direction and strength. J Clin Epidemiol 2013;66:726-35.

21. Hultcrantz M, Rind D, Akl EA, et al. The GRADE Working Group clarifies the construct of certainty of evidence. J Clin Epidemio/ 2017;87:4-13.

22. Andersson I, Aspegren K, Janzon L, et al. Mammographic screening and mortality from breast cancer: the Malmö mammographic screening trial. BMJ 1988;297:943-8.

23. Nyström L, Andersson I, Bjurstam N, et al. Long-term effects of mammography screening: updated overview of the Swedish randomised trials. Lancet 2002;359:909-19.

24. Frisell J, Lidbrink E, Hellström L, et al. Follow-up after 11 years - update of mortality results in the Stockholm mammographic screening trial. Breast Cancer Res Treat 1997;45:263-70.

25. Bjurstam N, Björneld L, Warwick J, et al. The Gothenburg breast screening trial. Cancer 2003;97:2387-96.

26. Miller AB, To T, Baines $C J$, et al. The Canadian National Breast Screening Study- 1 : breast cancer mortality after 11 to 16 years of follow-up. A randomized screening trial of mammography in women age 40 to 49 years. Ann Intern Med 2002;137:305-12.

27. Miller AB, Baines CJ, To T, et al. Canadian National Breast Screening Study: 2. Breast cancer detection and death rates among women aged 50 to 59 years. CMAJ 1992; 147:1477-88.

28. Moss SM, Cuckle H, Evans A, et al.; Trial Management Group. Effect of mammographic screening from age 40 years on breast cancer mortality at 10 years' followup: a randomised controlled trial. Lancet 2006;368:2053-60.

29. Shapiro S, Venet W, Strax P, et al. Ten- to fourteen-year effect of screening on breast cancer mortality. J Natl Cancer Inst 1982;69:349-55.

30. Tabár L, Fagerberg G, Chen HH, et al. Efficacy of breast cancer screening by age. New results from the Swedish Two-County Trial. Cancer 1995;75:2507-17.

31. Guyatt GH, Oxman AD, al Kunz R; GRADE Working Group. GRADE guidelines: 7. Rating the quality of evidence - inconsistency. J Clin Epidemiol 2011;64:1294-302.

32. Sun X, loannidis PA, Agoritas T, et al. How to use a subgroup analysis: users' guide to the medical literature. JAMA 2014;311:405-11.

33. Nyström L, Bjurstam N, Jonsson $\mathrm{H}$, et al. Reduced breast cancer mortality after $20+$ years of follow-up in the Swedish randomized controlled mammography trials in Malmö, Stockholm, and Götenborg. J Med Screen 2017;24:34-42.

34. Moss SM, Wale C, Smith R, et al. Effect of mammographic screening from age 40 years on breast cancer mortality in the UK Age trial at 17 years' follow-up: a randomised controlled trial. Lancet Oncol 2015;16:1123-32.

35. Tabár L, Vitak B, Chen TH-H, et al. Swedish two-county trial: impact of mammographic screening on breast cancer mortality during 3 decades. Radiology 2011;260:658-63

36. Shapiro $S$, Venet $W$, Strax $P$, et al. Current results of the breast cancer screening randomized trial. In: Day NE, Miler AB, editors. Screening for breast cancer. The Health Insurance Plan (HIP) of Greater New York study. Toronto: Hans Huber; 1988:3-15.

37. Miller AB, Wall C, Baines CJ, et al. Twenty-five year follow-up for breast cancer incidence and mortality of the Canadian National Breast Screening Study: randomised screening trial. BMJ 2014;348:g366.

38. Zackrisson S, Andersson I, Janzon L, et al. Rate of over-diagnosis of breast cancer 15 years after end of Malmö mammographic screening trial: follow-up study. BMJ 2006;332:689-92.

39. Baines CJ, To T, Miller AB. Revised estimates of overdiagnosis from the Canadian National Breast Screening Study. Prev Med 2016;90:66-71.

40. Yen AM, Duffy SW, Chen TH, et al. Long-term incidence of breast cancer by trial arm in one county of the Swedish Two County Trial of mammographic screening. Cancer 2012;118:5728-32.

41. Lund E, Mode N, Waaseth M, et al. Overdiagnosis of breast cancer in the Norwegian Breast Cancer Screening Program estimated by the Norwegian Women and Cancer cohort study. BMC Cancer 2013;13:614

42. Puliti D, Miccinesi G, Zappa M, et al. Balancing harms and benefits of service mammography screening programs: a cohort study. Breast Cancer Res 2012;14:R9.

43. Hellquist BN, Duffy SW, Nyström L, et al. Overdiagnosis in the population-based service screening programme with mammography for women aged 40 to 49 years in Sweden. J Med Screen 2012;19:14-9.

44. Njor SH, Olsen AH, Blichert-Toft M, et al. Overdiagnosis in screening mammography in Denmark: population based cohort study. BMJ 2013;346:f1064
45. Jørgensen KJ, Gøtzsche PC, Kalager M, et al. Breast cancer screening in Denmark: a cohort study of tumor size and overdiagnosis. Ann Intern Med 2017;166:313-23.

46. Puliti D, Bucchi L, Mancini S, et al.; IMPACT COHORT Working Group. Advanced breast cancer rates in the epoch of service screening: the 400,000 women cohort study from Italy. Eur J Cancer 2017;75:109-16.

47. Knowledge Synthesis Group. False positive and false positive biopsy calculations (Breast Cancer Screening Cohort) (Revised) (Prepared by the Ottawa Methods Centre, Ottawa Hospital Research Institute for the Canadian Task Force on Preventive Health Care under contract by the Public Health Agency of Canada). CTFPHC; 2018. Available: www.canadiantaskforce.ca (accessed 2018 Mar. 12).

48. Thomas DB, Gao DL, Ray RM, et al. Randomized trial of breast self-examination in Shanghai: final results. J Natl Cancer Inst 2002;94:1445-57.

49. Semiglazov VF, Manikhas AG, Moiseyenko VM, et al. Results of a prospective randomized investigation [Russia (St. Petersburg)/WHO] to evaluate the significance of self-examination for the early detection of breast cancer [article in Russian]. Vopr Onkol 2003;49:434-41.

50. Henriksen MJ, Guassora AD, Brodersen J. Preconceptions influence women's per ceptions of information on breast cancer screening: a qualitative study. BMC Res Notes 2015;8:404.

51. Hersch J, Jansen J, Barratt A, et al. Women's views on overdiagnosis in breast cancer screening: a qualitative study. BMJ 2013;346:f158.

52. Waller J, Douglas E, Whitaker KL, et al. Women's responses to information about overdiagnosis in the UK breast cancer screening programme: a qualitative study. BMJ Open 2013;3:e002703.

53. Driedger SM, Annable G, Brouwers M, et al. Can you un-ring the bell? A qualitative study of how affect influences cancer screening decisions. BMC Cancer 2017;17:647.

54. Toledo-Chávarri A, Rué M, Codern-Bové N, et al.; InforMa Study Group. A qualitative study on a decision aid for breast cancer screening: views from women and health professionals. Eur J Cancer Care (Engl) 2017;26. doi: 10.1111/ecc.12660.

55. Baena-Cañada JM, Rosado-Varela P, Expósito-Álvarez I, et al. Using an informed consent in mammography screening: a randomized trial. Cancer Med 2015;4:1923-32.

56. Bourmaud A, Soler-Michel P, Oriol M, et al. Decision aid on breast cancer screening reduces attendance rate: results of a large-scale, randomized, controlled study by the DECIDEO group. Oncotarget 2016;7:12885-92.

57. Gummersbach E, in der Schmitten J, Mortsiefer A, et al. Willingness to participate in mammography screening: a randomized controlled questionnaire study of responses to two patient information leaflets with different factual content. Dtsch Arztebl Int 2015;112:61-8.

58. Haakenson CP, Vickers KS, Cha SS, et al. Efficacy of a simple, low-cost educational intervention in improving knowledge about risks and benefits of screening mammography. Mayo Clin Proc 2006;81:783-91.

59. Hersch J, Barratt A, Jansen J, et al. Use of a decision aid including information on overdetection to support informed choice about breast cancer screening: a randomised controlled trial. Lancet 2015;385:1642-52.

60. Mathieu E, Barratt A, Davey HM, et al. Informed choice in mammography screening: a randomized trial of a decision aid for 70-year-old women. Arch Intern Med 2007;167:2039-46.

61. Mathieu E, Barratt AL, McGeechan K, et al. Helping women make choices about mammography screening: an online randomized trial of a decision aid for 40-yearold women. Patient Educ Couns 2010;81:63-72.

62. Saver BG, Mazor KM, Luckmann R, et al. Persuasive interventions for controversial cancer screening recommendations: testing a novel approach to help patients make evidence-based decisions. Ann Fam Med 2017;15:48-55.

63. Seitz HH, Gibson L, Skubisz C, et al. Effects of a risk-based online mammography intervention on accuracy of perceived risk and mammography intentions. Patient Educ Couns 2016;99:1647-56.

64. Elkin EB, Pocus VH, Mushlin Al, et al. Facilitating informed decisions about breast cancer screening: development and evaluation of a web-based decision aid for women in their 40s. BMC Med Inform Decis Mak 2017;17:29.

65. Berens EM, Reder M, Razum O, et al. Informed choice in the German mammog raphy screening program by education and migrant status: survey among firsttime invitees. PLoS One 2015;10:e0142316.

66. Davey C, White V, Gattellari M, et al. Reconciling population benefits and women's individual autonomy in mammographic screening: in-depth interviews to explore women's views about 'informed choice'. Aust N Z J Public Health 2005;29:69-77.

67. Lawrence VA, Streiner D, Hazuda HP, et al. A cross-cultural consumer-based decision aid for screening mammography. Prev Med 2000;30:200-8.

68. Nekhlyudov L, Li R, Fletcher SW. Informed decision-making before initiating screening mammography: does it occur and does it make a difference? Health Expect 2008;11:366-75.

69. Petrova D, Garcia-Retamero R, Cokely ET. Understanding the harms and benefits of cancer screening: a model of factors that shape informed decision-making. Med Decis Making 2015;35:847-58

70. Van den Bruel A, Jones C, Yang Y, et al. People's willingness to accept overdetection in cancer screening: population survey. BMJ 2015;350:h980. 
71. Wong IO, Lam WW, Wong CN, et al. Towards informed decisions on breast cancer screening: Development and pilot testing of a decision aid for Chinese women. Patient Educ Couns 2015;98:961-9.

72. Schwartz LM, Woloshin S, Sox HC, et al. US women's attitudes to false positive mammography results and detection of ductal carcinoma in situ: cross sectional survey. BMJ 2000;320:1635-40.

73. Lewis CL, Pignone MP, Sheridan SL, et al. A randomized trial of three videos that differ in the framing of information about mammography in women 40 to 49 years old. J Gen Intern Med 2003;18:875-83.

74. Schonberg MA, Hamel MB, Davis RB, et al. Development and evaluation of a decision aid on mammography screening for women 75 years and older. JAMA Intern Med 2014;174:417-24.

75. Waller J, Whitaker KL, Winstanley K, et al. A survey study of women's responses to information about overdiagnosis in breast cancer screening in Britain. Br J Cancer 2014;111:1831-5.

76. Gyrd-Hansen D. Cost-benefit analysis of mammography screening in Denmark based on discrete ranking data. Int J Technol Assess Health Care 2000;16:811-21.

77. Yasunaga H, Ide H, Imamura T, et al. Women's anxieties caused by false positives in mammography screening: a contingent valuation survey. Breast Cancer Res Treat 2007;101:59-64.

78. Paul C, Nicholls R, Priest P, et al. Making policy decisions about population screening for breast cancer: the role of citizens' deliberation. Health Policy 2008;85:314-20.

79. Mittmann N, Stout NK, Lee P, et al. Total cost-effectiveness of mammography screening strategies. Health Rep 2015;26:16-25.

80. Barry MJ, Edgman-Levitan S. Shared decision making - pinnacle of patientcentered care. N Engl J Med 2012;366:780-1.

81. Elwyn G, Frosch D, Thomson R, et al. Shared decision-making: a model for clinical practice. J Gen Intern Med 2012;27:1361-7.

82. Grad R, Légaré $F$, Bell N, et al. Shared decision-making in preventive health care: What it is; what it is not. Can Fam Physician 2017;63:682-4.
83. McCormack VA, dos Santos Silva I. Breast density and parenchymal patterns as markers of breast cancer risk: a meta-analysis. Cancer Epidemiol Biomarkers Prev 2006;15:1159-69.

84. Boyd NF, Guo H, Martin LJ, et al. Mammographic density and the risk and detection of breast cancer. N Engl J Med 2007;356:227-36.

85. Gierach GL, Ichikawa L, Kerlikowske K, et al. Relationship between mammographic density and breast cancer death in the Breast Cancer Surveillance Consortium. J Natl Cancer Inst 2012;104:1218-27.

86. Sprague BL, Gangnon RE, Burt V, et al. Prevalence of mammographically dense breasts in the United States. J Natl Cancer Inst 2014;106:dju255.

87. Melnikow JM, Fenton JJ, Whitlock EP, et al. Supplemental screening for breast cancer in women with dense breasts: a systematic review for the U.S. Preventive Services Task Force. Evidence Synthesis No. 126. AHRQ Publication No. 14-05201-EF-3. Rockville (MD): Agency for Healthcare Research and Quality; 2016.

88. Siu AL; U.S. Preventive Services Task Force. Screening for breast cancer: U.S. Preventive Services Task Force recommendation statement. Ann Intern Med 2016;164:279-96.

89. Oeffinger KC, Fontham ETH, Etzioni R, et al.; American Cancer Society. Breast cancer screening for women at average risk: 2015 guideline update from the American Cancer Society. JAMA 2015;314:1599-614.

90. Breast screening: programme overview [guidance]. London (UK): Public Health England; 2015 June 1. Available: www.gov.uk/guidance/breast-screening -programme-overview (accessed 2017 Oct. 10).

91. Early detection of breast cancer. Surry Hills (Australia): Cancer Australia 2004 (updated 2009, revised 2015). Available: https://canceraustralia.gov.au/ publications-and-resources/position-statements/early-detection-breast-cancer (accessed 2017 Oct. 10).

92. Hanley JA, McGregor M, Liu Z, et al. Measuring the mortality impact of breast cancer screening. Can J Public Health 2013;104:e437-42.

\begin{abstract}
Authors: Scott Klarenbach MD MSc, Nicki Sims-Jones RN MScN, Gabriela Lewin MD, Harminder Singh MD MPH, Guylène Thériault MD, Marcello Tonelli MD SM, Marion Doull PhD, Susan Courage RN BScN, Alejandra Jaramillo Garcia MSc, Brett D. Thombs PhD; Canadian Task Force on Preventive Health Care
\end{abstract}

\section{Competing interests: None declared.}

This article has been peer reviewed.

Affiliations: Department of Medicine (Klarenbach), University of Alberta, Edmonton, Alta.; Department of Family Medicine (Lewin), University of Ottawa, Ottawa, Ont.; Departments of Internal Medicine and Community Health Sciences (Singh), University of Manitoba, Winnipeg, Man.; Department of Family Medicine (Thériault), McGill University, Montréal, Que.; Department of Medicine (Tonelli), University of Calgary, Calgary, Alta.; Public Health Agency of Canada (Sims-Jones, Courage, Doull, Jaramillo Garcia), Ottawa, Ont.; Department of Psychiatry (Thombs), McGill University, Montréal, Que.

Guideline Writing Group: Scott Klarenbach (voting Task Force member), Nicki Sims-Jones (non-voting member of Public Health Agency of Canada [PHAC] scientific support team), Gabriela Lewin (voting Task Force member), Harminder Singh (voting Task Force member), Guylène Thériault (voting Task Force member), Marcello Tonelli (voting Task Force member), Marion Doull (non-voting member of PHAC scientific support team), Susan Courage (nonvoting member of PHAC scientific support team), Alejandra Jaramillo Garcia (non-voting member of PHAC scientific support team), Brett D. Thombs (voting Task Force member).

Collaborating members of the Canadian Task Force for Preventive Health Care: Heather Colquhoun, James Dickinson, Roland Grad, Stéphane Groulx, Eddy Lang, John Leblanc, Ainsley Moore, Donna Reynolds, Brenda Wilson. The complete list of all current members of the Canadian Task Force on Preventive Health Care is available at http:// canadiantaskforce.ca/about/members.

Contributors: Scott Klarenbach, Nicki SimsJones, Gabriela Lewin, Harminder Singh, Guylène Thériault, Marcello Tonelli, Marion Doull, Susan Courage, Alejandra Jaramillo Garcia and Brett Thombs contributed substantially to the study concept and design, interpretation of the evidence and critical revision of the guideline draft. Nicki Sims-Jones, Susan Courage, Marion Doull and Alejandra Jaramillo Garcia provided scientific and logistical support to the writing group. Scott Klarenbach, Heather Colquhoun, James Dickinson, Roland Grad, Stéphane Groulx, Gabriela Lewin, Eddy Lang, John Leblanc, Ainsley Moore, Donna Reynolds, Harminder Singh, Guylène Thériault, Brett Thombs, Marcello Tonelli and Brenda Wilson drafted the recommendations. Scott Klarenbach, Nicki Sims-Jones, Susan Courage, Marion Doull and Alejandra Jaramillo Garcia drafted the guideline statement. All of the named authors gave final approval of the version of the guideline to be published and agreed to be accountable for all aspects of the work. All collaborating members of the Canadian Task Force on Preventive Health Care also made contributions to the development of the guideline and all gave final approval of the version of the guideline to be published.

Funding: Funding for the Canadian Task Force on Preventive Health Care is provided by the Public Health Agency of Canada. The views of the funding body have not influenced the content of the guideline. The views expressed in this article are those of the Task Force and do not necessarily represent those of the Public Health Agency of Canada.

Acknowledgements: The authors would like to thank the Ottawa Hospital Research Institute and University of Alberta Evidence Review and Synthesis Centre teams (Pauline Barbeau, Adrienne Stevens, Andrew Beck, Becky Skidmore, Angel Arnaout, Muriel Brackstone, Alexandra Ginty, Amanda Hey, Brian Hutton, Beverley Shea, David Moher and Julian Little of the Ottawa Hospital Research Institute, and Jennifer Pillay, Tara MacGregor, Lisa Hartling and Robin Featherstone of the University of Alberta) for the evidence reviews that supported this guideline. The authors also thank the Knowledge Translation Program, Li Ka Shing Knowledge Institute, St. Michael's Hospital for their contributions to patient engagement and knowledge translation work related to this guideline. Additionally, the authors thank peer reviewers and organizational stakeholders who provided feedback on the draft guideline.

Correspondence to: Canadian Task Force on Preventive Health Care, info@canadiantaskforce.ca 